\title{
ANATOMY FOR NURSES: PROVIDING STUDENTS WITH THE BEST LEARNING EXPERIENCES
}

Thanks to anatomy lab staff

Key words: nurses, human anatomy, dissection, prosection

\begin{abstract}
A good understanding of human anatomy is clinically relevant for many health care professionals. A detailed knowledge of where, as well as how, to palpate, percuss or auscultate is essential for adequate assessment, provision of treatment and ongoing care of patients. Thus, the linking of human anatomy and clinical assessment is essential. However, Australian nursing students are often excluded from experiences, such as exposure to cadaveric material, which might enable them to gain a good working knowledge of internal human anatomy. Herein systematic student feedback from nursing students who were provided with a single exposure to prosected human anatomical material and were able to manipulate and interact with that material is presented, in the context of the integrative educational aims and goals of this learning and teaching activity. Thus, this study aims to add to the literature informing ongoing dialog regarding the best set of tools to teach anatomy to students of nursing.
\end{abstract}




\section{INTRODUCTION: Anatomical education for nurses}

Nursing education, like many areas of health profession education, continues to evolve and develop in order to best serve and support the clinical and professional roles of its students. As with many 'core' modules in nursing (Lim and Honey 2006), anatomy has been taught either as a stand-alone course, or integrated into other, often clinical, courses. The common expectation is that anatomy/physiology courses will scaffold nurses' understanding of pathophysiology, clinical assessment and many nursing procedures (Jordan and Reid 1997). However these ‘introductory’ courses remain a difficult challenge for many nursing students, undertaken with considerable trepidation because of the typically high fail rates and due to the breadth and depth of new complex information presented (Courtenay 1991) Thus the presence, role and format of such courses in nursing programs continues to be questioned (Courtenay 1999; Davies et al., 2000; Diekelmann 2005; Jordan and Reid 1997).

Nursing students and newly qualified nurses report and are reported as being fearful of the biological sciences (Thornton 1997) and as having difficulties in applying anatomical and physiological information (Clancy et al., 2000; McVicar and Clancy 2001; Tanner 2003a). This relative inability to apply theoretical information impacts on patient care by preventing effective and efficient patient assessment and promoting communication processes that are fragmented and confusing; delaying effective treatment options (Andrews and Waterman 2005; Considine 2005; Considine and Botti 2004). Inability to accurately 'physiologically police' patients increases the risk of averse events, increasing mortality and morbidity (West 2006). Nurse educators need to explore different methods of delivery of these important topics. Any method which can emphasis and reinforce anatomical knowledge and particularly the relevance of anatomical learning to nursing students should be carefully examined 
and, where possible, implemented (Wilkes and Batts 1998). A balanced view of the role of the social, behavioural and biological sciences in nursing education (Pesut and Herman 1999) demands continued analysis of effective learning and teaching experiences of the sciences and science integration in nursing.

Thus demands for review of traditional models of nurse education are common and evidence-based. Course content and delivery should be and often is re-examined in light of changing professional responsibilities and a greater understanding of effective methods of educational process (Lim et al., 2007). Sometimes changes in educational process can come from within other areas of health-related training which are redefined and reapplied in alternate educational contexts. One such development, aligned with constructivist learning theory, currently being explored in some bachelor of nursing programs is the (re) exposure of nursing students studying human anatomy and physiology to cadaveric material.

\section{Some existing methods of teaching anatomy to nursing students: The common 'how' of teaching anatomy.}

The study of anatomy, for many nursing students and for many years, has relied heavily on surface learning of superficial anatomy, with primarily text, simulated or, more rarely, animal dissection enabling a deeper and more holistic and conceptual understanding of anatomical information. This has occurred despite literature in the field of medical education which strongly suggests that exposure to cadaveric dissection or even prosected (partially dissected and prepared specimens) material significantly increases depth of relevant and applicable anatomical knowledge (Bowsher 1976; Collett and McLachlan 2005; Dyer and Thorndike 2000; Nnodim 1990; Pandey and Zimitat 2007; Stansby 2004; Stillman et al., 1978; Winkelmann 
2007a). Use of dissection material in a laboratory situation is an opportunity to emphasise both rationalist and humanist ways of knowing. It is possible for the instructor to convey knowledge about the relevant organ system whilst also facilitating learners' personal feelings about mortality, humanity, objectification and understanding of how to be a dispassionate yet respectful clinician. It enables students to contextualize knowledge and thus enhances their ability to retain and subsequently apply anatomical information (Forneris and Peden-McAlpine 2006). It was with these learning objectives in mind that staff embarked on a limited laboratory extension program to the current anatomy courses. It was so overwhelmingly successful in the first delivery that it was repeated (3 times to date). This was an exploratory investigation into the use and applicability of such experience.

\section{Method: The laboratory experience}

The laboratory experiences were held at the end of the first year of (undergraduate) bachelor of nursing courses (2) covering human anatomy and physiology. They are conducted in the dedicated anatomy labs open to 'health' group teaching courses in the University. They include primarily first, but also some second year students. Each laboratory session consists of a short ( 2 hour) exposure to 6 prosected specimens of increasing anatomical complexity (lower limb, upper limb, lower quadrant, upper quadrant, torso, full body), repeated 3 times to maximise the number of students able to attend. Following detailed briefings on student conduct, behaviour and safety, and some background to the collection and preparation of the specimens on display, small groups ( 25) students are exposed to each of the specimens in turn by a nurse-trained demonstrator. The demonstrator, assisted by the anatomy lecturer, spends some time explaining and outlining the potentially relevant areas of the 
specimen, the clinical and applied significance of the anatomical features displayed and any gross pathophysiological features of the specimen. Display and discussion foci included areas such as the cross-sectional shape and location of the urethra, the oesophagus, trachea and the nasal cavity; the size, shape and location of the heart and lung fields; the location of large nerve tracts such as the sciatic nerve and the volume, location and thickness of large skeletal muscle groups such as the deltoids and quadriceps group. Students are then invited to carefully explore and interact with each specimen in the presence of the demonstrator/lecturer so they can gain hands-on experience of the relative location, size and features of various muscle groups, organs and organ systems and fatty/connective tissues. Students are given a brief, informal debrief immediately following the laboratory and a more extensive debrief in their class subsequent to the laboratory time.

\section{Results of Evaluation}

Each year a number of students (15-26) give spontaneous feedback both verbally and via email to the lecturer following the experience, while $\sim 85 \%$ (189) of students voluntarily completed an anonymous 8-question, likert-scale based feedback forms about their experience (cf $\sim 45-75 \%$ who complete standard anonymous course feedback forms in the same semesters). Data and comments from these feedback forms are included in Table 1 and the discussion below. Formal ethical clearance was not required under the rules set by the National and University Ethics committee, since data collected was part of the routine course evaluation undertaken in a usual semester. Even so, students are required to understand course evaluation data requests and completion is understood to be consent. All students had (and some 
took) the opportunity to anonymously avoid participation in the study or to decline to answer specific questions.

Positive student response to the opportunity to participate in laboratory exposure to human cadaveric material was overwhelming. Available places are almost $30 \%$ oversubscribed every year despite the proximity to the exam period (held in the last 2 weeks of semester) and the costs to students associated with laboratory coat hire and personal transport. Moreover the majority of students in the anatomy and physiology course, even those opting not to attend (it was entirely voluntary), welcomed the opportunity to be exposed to such an experience.

Students' responses indicated that they appreciated the experience, with over 96\% recommending or strongly recommending it to their peers. Perhaps somewhat surprising was that more students recognised its important to their future nursing practice (78\% totally relevant) than students recognising it as totally relevant to their study of anatomy and physiology (65\%) perhaps reflecting the very clinical emphasis placed on the experience and topics covered during the experience - but in both cases more than $85 \%$ of students felt it was very or pretty relevant to their study areas. Student data supported the faculty view in suggesting that it was not an experience which needed to be repeated regularly (only $40 \%$ opted strongly for a repeat visit). Moreover, it was clear that the students, while finding it a challenging and confronting experience, mostly felt safe and reassured by the experience.

It could certainly be argued that the most motivated and interested students opted to attend - biasing feedback responses. It is, however, of interest that a there was concomitant and consistent drop in failure rate in these courses of around 8-12\% since the induction of this and other small innovations. 


\section{Discussion: 'Evaluation contextualized'}

Discussions of the use of human cadaveric material in training of health professionals often focus on what sort of anatomical information specific health care workers might actually require. An argument has been made that most health professionals, including nurses, almost exclusively encounter living surface human anatomy in the course of their professional responsibilities (McLachlan 2004) and thus it is surface anatomy which is most important to teach and reinforce in these students. However nursing students, along with other health care professionals, are required on a routine basis to use surface anatomy in order to probe and assess deeper structures. Without an ability to visualize the position of such deeper organs, to understand where they are and how they relate to other organs, it is more difficult for nursing students to develop holistic clinical assessment of patients. Use of prosected material with which students were able to interact enabled students to, in a supervised and directed manner, turn back layers of muscle and fat, to move, and thus understand, the relative positions of bony masses such as the ribs and pelvic cavity compared to the soft organs and tissues such as bowel, liver and large nerve tracts. It gives them some appreciation of the variation in organ position and size and concomitant variation in surface anatomy. It also begins the process of contextualization and application of this new knowledge to clinical assessments which is not able to be provided as effectively by a twodimensional text or an idealized model (Fredricks and Wegner 2003).

Students' comments indicating the success of this strategy included:

“ ...they said never give an IM injection into the backside - but now I see where the sciatic nerve is - just under the muscle mass, I can see how easy it would be hit or damage it.” 
"Wow - I never realised that the liver is so big and spread so far over the top of the bowel”

"I was taught the heart was on the left side of the chest, I never realised that it came so far over to the middle - but then I guess that's why CPR works. It was cool to see where the heart valves were compared to the ribs - made listening for heart sounds make a lot more sense”

Hands-on experience helped students to see rationales behind care principles and to apply anatomical knowledge to medical procedures. Exposure to the prosected material appeared to provide the students a better 'mental' picture of the dimensions, locations and some feel for variation in organ size and position. Cross-sectional observation of the rectal passage, vagina and the urethra in specimens clearly reinforced the catheterization procedures students had seen in clinical practice. Observation of the location and shape of trachea supported their text-based understanding of the processes used in in/extubation.

"It gave me a clear picture in my head of really where catheter tubes run - and now when I am using the models I 'see' where the [catheter] tube is moving and how far it might have to go. I think I would feel a bit more confident about giving an enema one day too” While studies examining the effectiveness of web-based teaching of clinical skills, such as ECG, indicate high levels of student motivation and satisfaction (Jang, Hwang, Park, Kim, \& Kim 2005), these studies often point to a need to enhance “motivation for more active learning” (p. 38). Results from this study suggest that one of the best motivators may well be interaction with real material in a hands-on 
way, which enables students to engage with, understand and then apply knowledge acquired in alternative contexts.

"It was an amazing experience and an opportunity for me to really solidify some concepts in my own mind (as well as shining a painfully bright light on topics I need to work on a bit harder). Do they take volunteer workers???!!!”

It appeared to enable nursing students to move from a relatively surface approach to learning (memorization) anatomy to a much deeper approach; enabling a better understanding of the relative position of internal organs in situ and their spatial interrelationships (Pandey and Zimitat 2007). It is clear that clinical anatomy students require a combination of memorization and visualization in order to effectively retain and apply knowledge (Pandey and Zimitat 2007) and yet nursing students are often excluded from such learning processes. Indeed, some commentators argue that science pedagogy within health education programs has not kept pace with advances in teaching the art of clinical practice (Bynum 1993; Weatherall 2006; Wynne et al., 1997), a deficit which is increasingly the focus of studies of nurse education, as more and more studies report dissatisfaction with science teaching and learning in nursing (Clancy et al., 2000; Johnston and McAllister 2008; McVicar and Clancy 2001; Mitchell et al., 2004; Wilkes and Batts 1998).

A number of studies using medical students have shown that exposure to anatomical material is an irreplaceable part of anatomical training (Stanford et al., 1994; Winkelmann 2007b). Despite this, many nursing programs remain dissection-free or void of exposure to human dissected/prosected materials. A literature search of the primary nursing database, CINAHL revealed no hits for combinations of any of the following key words: nursing, students with any of the following: dissection, 
prosection, cadavers, human anatomy, anatomy despite the plethora of literature in the medical journals (combination of dissection and human anatomy in PubMed showed 19,745 hits!). It seems educationally indefensible that, in this age of increasing professional responsibilities for registered nurses, known effective medical educational processes are not being adapted to best support these changing roles.

"Was good to see a real human body rather than textbooks. Was really interesting and a great learning exercise”

Tanner (Tanner 2003b) argues convincingly that simply focusing nursing science courses on technical procedures and processes does not best serve the needs of nursing students primarily because students are best served in the short-and longerterm by developing their own critical thinking skills, their own drive to explore and inquire. In order to engage students and deepen understanding, activities are required that stimulate inquiry and critical thinking. Surely as we enter this new century we recognise that exposure to valuable teaching resources such as prosected human cadavers, albeit limited, may be as valuable for nurses as their medical colleagues, preparing students of nursing for competent clinical practice.

The explosion of knowledge in the biological sciences and the consequential development of many more surgical and medical procedures and treatments has resulted in ongoing development and expansion of the role of nurses (Carvalho 2003; Courtenay 1991; Nyatanga 2005). This role is increasingly including detailed and ongoing physical assessment by nurses, implicit in which is an understanding of functional human anatomy (West 2006). These factors, coupled with an increasingly aging population and thus, a greater number of patients with multiple pathologies means that all health care providers, including nurses, need a good understanding of 
the complexities of anatomy and physiology, an understanding which should be met, at least in part, by their undergraduate education program.

\section{Incidental benefits of exposure to prosected human specimens}

It is clear that exposure to human cadaveric material is quite stressful for students (Charlton and Smith 2000; Finkstein and Mathers 1990) and this must be considered in any educational program. However, a small amount of stress is know to enhance salience of learning experiences and enhance retention of learnt material in people (Andreano and Cahill 2006; Shors 2006). This was reflected in student feedback.

"I will never forget seeing the inside of that person. I can close my eyes and 'see' it ......"

" I found the experience a real additive to my nursing studies, now being able to visualise more confidently and put into perspective different aspects of the human body”

Despite the vivid images the students describe and the concern they reported prior to and following the experience, the vast majority of students were overwhelmingly positive about the learning opportunity. Many reported relief in being able to view a cadaver in a contained situation, with equally inexperienced peers

"I got over my fear of seeing a dead person for the first time. If I had not seen the human body in such a close up, I would not have imagined what bones, muscles, tendons, veins and arteries look like...”

This would seem to be particularly valuable for nursing staff who are often responsible for post-mortem arrangement of deceased and supporting bereaved friends and relatives. Introduction to death is an important part of a program of education for health care professionals (Garrison 2003; Kelly and Yetman 1987), but 
can lack meaning in the absence of actual exposure to a deceased person. (Kurz and Hayes 2006; Williams et al., 2005). There was certainly no evidence in behaviour during the session, informal comments prior to or following the session or in subsequent discussions that this experience might increase insensitivity or callousness to death and dying or the treatment of deceased persons (Francis and Lewis 2001).

\section{Practical issues associated with exposure to prosected specimens}

While it is clearly the case that exposure to anatomical models is expensive (Fitzharris 1998), some of this cost can be reduced by the repeated use of fixed prosected specimens, which appear to offer an approximately equivalent experience (Nnodim 1990). Moreover, nursing education is often conducted at Educational Institutes which also offer other health professional training programs which include some exposure to human anatomical material as a matter of course. Thus, safety issues associated with the use of either fresh specimens and/or the fixative agents used with preserved specimens have usually been dealt with in an appropriate manner. Moreover, standardized laboratory briefing and debriefing procedures are easily modified for nursing students. Despite this, very few nursing programs appear to standardly offer students experience (however limited) with cadaveric material.

\section{CONCLUSIONS}

Spontaneous comments and feedback from nursing students exposed to human prosected specimens as a voluntary part of their anatomical and physiological studies echoed, with surprising veracity, the pedagogical aims of staff in initiating and supporting this experience. The students clearly valued this experience highly and it appeared to effectively support their personal progression from learnt knowledge to 
professional and clinical application of such knowledge. As such it provides another 'weapon' in our arsenal of tools to demystify and enhance the application of particularly anatomical knowledge to practical patient care; helping to train better, more experienced and confident nursing graduates. It also indicates how a single 'high -affect' learning experience at the conclusion of a study period can be used to integrate and provide meaning to content from across the first year curriculum from A\&P to assessment and clinical nursing practice with apparent concomitant academic reward. 
Table 1:

1. How interesting did you find the trip to the Gold Coast anatomy facility?

Total waste of time $\square$ Not very $\square$ It was OK $\square$ Pretty good $\square$ Absolutely fascinating $\square$

Other: Please specify

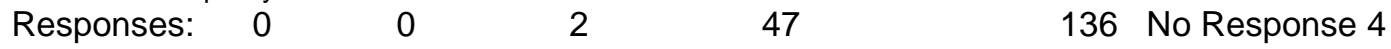

2. How relevant was the experience to your study of anatomy and physiology?

Total waste of time $\square$ Not very $\square$ It was OK $\square$ Pretty good $\square$ Totally relevant $\square$

Other: Please specify

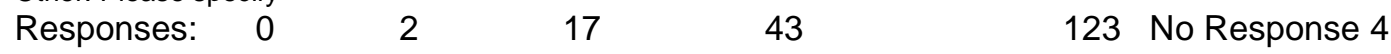

3. How relevant was the experience to your understanding of some nursing practises?

Total waste of time $\square$ Not very $\square$ It was OK $\square$ Pretty good $\square$ Totally relevant $\square$

Other: Please specify

$\begin{array}{llllll}\text { Responses: } & 0 & 0 & 46 & 148 & \text { No Response } 1\end{array}$

4. Would you recommend students attend if the opportunity were offered again next year?

Definitely not $\square$ Maybe $\square$ Yes, if they had time $\square$ Definitely $\square$ They would be mad not to go $\square$

Other: Please specify

$\begin{array}{lllllll}\text { Responses: } & 0 & 0 & 6 & 18 & 164 & \text { No Response } 1\end{array}$

5. Would you welcome the opportunity to attend again next year?

Definitely not $\square$ Maybe $\square$ Yes, if I had time $\square \quad$ Definitely $\square \quad$ I would be mad not to go $\square$

Other: Please specify

$\begin{array}{lllllll}\text { Responses: } & 0 & 51 & 63 & 38 & 37 & \text { No Response } 0\end{array}$

6. How carefully and sensitively do you think the staff deal with the issues associated with cadaver use.

Totally insensitive $\square$ superficial only $\square$ they were OK $\square$ Pretty good $\square$ They were very sensitive and appropriately careful $\square$

Other: Please specify

$\begin{array}{llllll}\text { Responses: } & 0 & 1 & 5 & 46 & 135 \text { No Response } 2\end{array}$

7. How safe did you feel (personally) in the laboratory space?

Very unsafe $\square$ unsafe $\square$ OK if nothing went wrong $\square$ Scary but OK $\square$ Felt totally safe $\square$

Other: Please specify

$\begin{array}{lllllll}\text { Responses: } & 0 & 1 & 9 & 134 & 42 & \text { No Response } 3\end{array}$

8. How useful and interesting did you find the demonstrator,

Totally boring \& often inappropriate $\square$ Not really very useful and interesting $\square$ OK - maybe $\square$ Pretty useful and interesting $\square$ Totally fantastic $\square$

Other: Please specify

$\begin{array}{lrlllll}\text { Responses: } & 2 & 8 & 56 & 87 & 35 & \text { No Response } 1\end{array}$

Any other comments you would like to make? (Timing of trip? duration of trip? lab exercises? Preparation? De-brief? Etc)

\section{Conflict of interest}

I have no financial or personal relationship with other people or organizations that

could inappropriately influence or bias this work. 


\section{References}

Andreano, J. M., Cahill, L., 2006. Glucocorticoid release and memory consolidation in men and women. Psychological Science 17 (6), 466-470.

Andrews, T., Waterman, H., 2005. Packaging: a grounded theory of how to report physiological deterioration effectively. Journal of Advanced Nursing 52 (5), 473-481.

Bowsher, D., 1976. What should be taught in anatomy? Medical Education 10 (2), 132-134.

Bynum, W. (1993). Science in medicine: How far has it advanced? London: Office of Health Economics.

Carvalho, V., 2003. About epistemological constructs in science -- a contribution to nursing [Portuguese]. Revista Latino Americana de Enfermagem 11 (4), 420428.

Charlton, R., Smith, G., 2000. Undergraduate medical students' views on the value of dissecting. Medical Education 34 (11), 961.

Clancy, J., McVicar, A., Bird, D., 2000. Getting it right? An exploration of issues relating to the biological sciences in nurse education and nursing practice. Journal of Advanced Nursing 32 (6), 1522-1532.

Collett, T. J., McLachlan, J. C., 2005. Does 'doing art' inform students' learning of anatomy? Medical Education 39 (5), 521.

Considine, J., 2005. The role of nurses in preventing adverse events related to respiratory dysfunction: literature review. Journal of Advanced Nursing 49 (6), 624-633.

Considine, J., Botti, M., 2004. Who, when and where? Identification of patients at risk of an in-hospital adverse event: implications for nursing practice. International Journal of Nursing Practice 10 (1), 21-31.

Courtenay, M., 1991. A study of the teaching and learning of the biological sciences in nurse education. Journal of Advanced Nursing 16 (9), 1110-1116.

Courtenay, M., 1999. Why the biological sciences should be back in the curriculum. NT Learning Curve 3 (6), 8-9.

Davies, S., Murphy, F., Jordan, S., 2000. Bioscience in the pre-registration curriculum: finding the right teaching strategy. Nurse Education Today 20 (2), 123-135.

Diekelmann, N. L., 2005. Guest editorial. Creating an inclusive science for nursing education. Nursing Education Perspectives 26 (2), 64-65.

Dyer, G. S., Thorndike, M. E., 2000. Quidne mortui vivos docent? The evolving purpose of human dissection in medical education. Academy of Medicine 75 (10), 969-979.

Finkstein, P., Mathers, L., 1990. Post-traumatic stress among medical students in the anatomy dissection laboratory. Clinical Anatomy 3, 219-226.

Fitzharris, T. P., 1998. Survey of gross anatomy courses in the United States and Canada. Anatomical Record 253 (6), 162-166.

Forneris, S. G., Peden-McAlpine, C. J., 2006. Contextual learning: a reflective learning intervention for nursing education. International Journal of Nursing Education Scholarship 3 (1), 1-18.

Francis, N. R., Lewis, W., 2001. What price dissection? Dissection literally dissected. Medicine and Humanities 27 (1), 2-9. 
Fredricks, K. T., Wegner, W. M., 2003. Clinical relevance of anatomy and physiology: a senior/freshman mentoring experience. Nurse Education 28 (5), 197-199.

Garrison, D., 2003. Correspondence. Journal of Allied health 32 (1), 62.

Johnston, A. N. B., McAllister, M., 2008. Back to the future with hands-on science. Journal of Nursing Education 7 (9), 417-421.

Jordan, S., Reid, K., 1997. The biological sciences in nursing: an empirical paper reporting on the applications of physiology to nursing care. Journal of Advanced Nursing 26 (1), 169-179.

Kelly, C., Yetman, L., 1987. At the end of life... knowledge of the physical stages of dying. Canadian Nurse 83 (4), 33-34.

Kurz, J. M., Hayes, E. R., 2006. End of life issues action: impact of education. International Journal of Nursing Education Scholarship 3 (1), 1-13.

Lim, A. G., Honey, M., 2006. Integrated undergraduate nursing curriculum for pharmacology. Nurse Education in Practice 6, 163-168.

Lim, A. G., Honey, M., Kilpatrick, J., 2007. Framework for teaching pharmacology to prepare graduate nurse for prescribing in New Zealand. Nurse Education in Practice 7 (5), 348-353.

McLachlan, J. C., 2004. New path for teaching anatomy: living anatomy and medical imaging vs. dissection. Anatomical Record B New Anatomy 281 (1), 4-5.

McVicar, A., Clancy, J., 2001. Education. The biosciences and Fitness for Practice: a time for review? British Journal of Nursing 10 (21), 1415-1420.

Mitchell, B. S., McCrorie, P., Sedgwick, P., 2004. Student attitudes towards anatomy teaching and learning in a multiprofessional context. Medical Education 38 (7), 737-748.

Nnodim, J. O., 1990. Learning human anatomy: by dissection or from prosections? Medical Education 24 (4), 389-395.

Nyatanga, L., 2005. Nursing and the philosophy of science. Nurse Education Today 25 (8), 670-674; discussion 675-677.

Pandey, P., Zimitat, C., 2007. Medical students' learning of anatomy: memorisation, understanding and visualisation. Medical Education 41 (1), 7-14.

Pesut, D., Herman, J. (1999). Clinical Reasoning: The Art and Science of Critical and Creative Thinking. Albany: Delmar.

Shors, T. J., 2006. Stressful experience and learning across the lifespan. Annual Review of Psychology 57, 55-85.

Stanford, W., Erkonen, W. E., Cassell, M. D., Moran, B. D., Easley, G., Carris, R. L., Albanese, M. A., 1994. Evaluation of a computer-based program for teaching cardiac anatomy. Investigations in Radiology 29 (2), 248-252.

Stansby, G., 2004. Teaching anatomy without cadavers. Medical Education 38 (8), 911; author reply 912-913.

Stillman, P. L., Ruggill, J. S., Sabers, D. L., 1978. The use of live models in the teaching of gross anatomy. Medical Education 12 (2), 114-116.

Tanner, C. A., 2003a. Science and nursing education. Journal of Nurse Education 42 (1), 3-4.

Tanner, C. A., 2003b. Science and nursing education. Journal of Nursing Education $42(1), 3-4$.

Thornton, T., 1997. Attitudes towards the relevance of biological, behavioural and social sciences in nursing education. Journal of Advanced Nursing 26 (1), 180-186. 
Weatherall, D. J., 2006. Science in the undergraduate curriculum during the 20th century. Medical Education 40 (3), 195-201.

West, S. L., 2006. Physical assessment: whose role is it anyway? Nursing Critical Care 11 (4), 161-167.

Wilkes, L. M., Batts, J. E., 1998. Nurses' understanding of physical science in nursing practice. Nurse Education Today 18 (2), 125-132.

Williams, C. M., Wilson, C. C., Olsen, C. H., 2005. Dying, death, and medical education: student voices. Journal of Palliative Medicine 8 (2), 372-381.

Winkelmann, A., 2007a. Anatomical dissection as a teaching method in medical school: a review of the evidence. Medical Education 41 (1), 15-22.

Winkelmann, A., 2007b. Anatomical dissection as teaching method in medical school: A review of evidence. Medical Education 41 (1), 15-22.

Wynne, N., Brand, S., Smith, R., 1997. Incomplete holism in pre-registration nurse education: the position of the biological sciences. Journal of Advanced Nursing 26 (3), 470-474.

Jang, K. S., Hwang, S. Y., Park, S. J., Kim, Y. M., Kim, M. J., 2005. Effects of a Web-based teaching method on undergraduate nursing students' learning of electrocardiography. Journal of Nursing Education 44 (1), 35-39. 